\title{
Investigation of airborne foot-and-mouth disease virus transmission during low-wind conditions in the early phase of the UK 2001 epidemic
}

\author{
T. Mikkelsen ${ }^{1}$, S. Alexandersen ${ }^{4}$, P. Astrup ${ }^{1}$, H. J. Champion ${ }^{2}$, A. I. Donaldson ${ }^{4}$, F. N. Dunkerley ${ }^{1}$, J. Gloster ${ }^{2}$, \\ J. H. Sørensen ${ }^{3}$, and S. Thykier-Nielsen ${ }^{1}$ \\ ${ }^{1}$ Risø National Laboratory, Roskilde, Denmark \\ ${ }^{2}$ Met Office, Bracknell, UK \\ ${ }^{3}$ Danish Meteorological Institute, Copenhagen, Denmark \\ ${ }^{4}$ Institute for Animal Health, Pirbright, UK
}

Received: 14 November 2002 - Published in Atmos. Chem. Phys. Discuss.: 10 February 2003

Revised: 18 November 2003 - Accepted: 18 November 2003 - Published: 28 November 2003

\begin{abstract}
Foot-and-mouth disease (FMD) is a highly contagious viral disease of cloven-hoofed domesticated and wild animals. The highly contagious nature of FMD is a reflection of the wide range of host species, the enormous quantities of virus liberated by infected animals, the range of excretions and secretions which can be infectious, the stability of the virus in the environment, the multiplicity of routes of infection and the very small doses of the virus that can initiate infection.
\end{abstract}

One of the mechanisms of spread is the carriage of droplets and droplet nuclei exhaled in the breath of infected animals. Such spread can be rapid and extensive, and it is known in certain circumstances to have transmitted disease over a distance of several hundred kilometres.

During the 2001 FMD epidemic in the United Kingdom (UK), atmospheric dispersion models were applied in real time in order to assess the potential for atmospheric dispersion of the disease. The operational value of such modelling is primarily to identify premises which may have been exposed so that the human resources for surveillance and disease control purposes are employed most effectively.

The paper describes the combined modelling techniques and presents the results obtained of detailed analyses performed during the early stages of the UK 2001 epidemic.

This paper investigates the potential for disease spread in relation to two outbreaks (Burnside Farm, Heddon-on-theWall and Prestwick Hall Farm, Ponteland, Northumberland). A separate paper (Gloster et al., 2002) provides a more detailed analysis of the airborne disease transmission in the vicinity of Burnside Farm.

Correspondence to: T. Mikkelsen

torben.mikkelsen@risoe.dk
The combined results are consistent with airborne transmission of disease to livestock in the Heddon-on-the-Wall area. Local topography may have played a significant role in influencing the pattern of disease spread.

\section{Introduction}

Animals infected with foot-and-mouth disease (FMD) exhale virus in their breath as droplets and droplet nuclei at various levels depending on the virus strain, disease stage, and animal species. For instance, pigs infected with certain strains of virus can emit more than three orders of magnitude more airborne virus than cattle or sheep.

The corresponding air concentrations downwind can vary by over two or three orders of magnitude, depending on the prevailing atmospheric conditions. The highest concentrations can be expected in stable, low-wind conditions, where there will be low levels of turbulence and hence minimal mixing.

In previous outbreaks it has been concluded that the quantities of viral emissions from pigs were sufficiently large for infectious concentrations to be present at a distance up to $100 \mathrm{~km}$ or more from the source, even in moderate winds (Sørensen et al., 2000).

This paper investigates the airborne spread of disease from Burnside Farm, Heddon-on-the-Wall, Northumberland, probably the site of introduction of FMD in the UK 2001 epidemic. 


\section{Airborne spread of foot-and-mouth disease}

Most commonly the movement of infected animals spreads FMD. Contact between infected and susceptible animals results in aerogenous transmission of infectious droplets and droplet nuclei. These particles originate mainly from the respiratory tract and are exhaled in the breath of infected animals. The next most common mechanism of spread is by the movement of contaminated animal products such as meat, milk etc. FMD virus can also be transmitted mechanically e.g. by contaminated vehicles and by people. In addition, FMD can be spread by the wind. This is not a common mechanism of spread, as it requires the simultaneous occurrence of particular epidemiological and climatic conditions. However, when it takes place it can be both rapid and extensive. For example, during the first 3 weeks of the 1967-1968 UK epidemic around 300 outbreaks were reported downwind of the primary outbreak. Simulation models have been developed which can be used to predict the risk of virus dissemination and the probable direction and distance of spread. This information can assist control procedures during emergencies as the manpower for surveillance activities can be directed in the most efficient manner (Donaldson and Alexandersen, 2002).

\section{The UK 2001 FMD epidemic}

The first outbreak of the 2001 FMD epidemic in the UK was reported on 20 February when disease was confirmed at an abattoir near Brentwood, Essex, which specialised in the processing of culled sows and boars. On 23 February the disease was also confirmed at a pig farm near Heddon-on-the-Wall in Northumberland. This was followed shortly after by disease being confirmed at additional premises in Essex, Northumberland and Devon. Alexandersen et al. (2002b, 2003) have given detailed accounts of the findings at five of the premises investigated during the early stages of the epidemic.

Within a matter of days disease was detected in many counties throughout the UK, including Wiltshire on 26 February; Anglesey, Durham, Herefordshire, Lancashire and Northumberland on 27 February; Leicestershire, Warwickshire and Powys on 28th February. The epidemic peaked on 26 March when 54 outbreaks were recorded.

It is clearly important to understand the epidemiology of the disease and in particular why it spread so rapidly in the initial stages.

\subsection{Burnside Farm}

In this paper we report a detailed investigation into the spread of disease from Burnside Farm, Northumberland in 2001, known as FMD Outbreak 4 (the fourth outbreak to be reported). Particular attention has been given to assessing the potential for airborne spread. This outbreak was selected, as it is believed to be one of the major sources for many other outbreaks during the 2001 epidemic and involved in excess of 100 pigs excreting virus (Alexandersen et al., 2002b).

\subsection{Epidemiological data}

The transmission of virus from Burnside Farm (FMD outbreak 4) at Heddon-on-the-Wall, to Prestwick Hall Farm (FMD Outbreak 6), located $6.4 \mathrm{~km}$ to the northeast near Ponteland, is investigated in detail because this transmission is believed to be critical for the spread of disease throughout the UK. Detailed descriptions of five early outbreaks during the epidemic, including Burnside Farm and Prestwick Hall Farm, have been recorded by Alexandersen et al. (2002b, 2003). Based on estimates of the age of FMD lesions observed in the pigs, Alexandersen et al. (2002b, 2003) considered that significant amounts of airborne virus may have been released from Burnside Farm in the period from 3 to 24 February.

Of significance to this study is that no means of disease spread other than by windborne carriage of virus have been identified as the method by which disease spread to Prestwick Hall Farm (i.e. no history of the movement of animals, people, or vehicles). Alexandersen et al. (2002b) in their account of their investigations at Prestwick Hall Farm also failed to establish any direct link to Burnside Farm. The only movement link from Burnside Farm was to the abattoir in Essex, where disease was first reported. The database records seven secondary outbreaks as "local spread", four as "airborne" and one "under investigation". Disease spread from two of these farms, in particular the movement of sheep from Prestwick Hall and Lough House, is believed to have been key to the rapid escalation of the epidemic throughout the UK. Animals from these farms were moved to Ponteland and Hexham Markets on 12 and 13 February, i.e. before the presence of FMD in the country was known.

FMD experts from IAH, Pirbright, have estimated the likely infection period for the outbreak at Prestwick Hall Farm. Infection is believed to have occurred between $25 \mathrm{Jan}$ uary and 14 February, dependent on whether sheep or cattle were actually the first infected animals. According to Alexandersen et al. (2002b, 2003) the first clinical disease could have been on 10 February if the lameness in sheep observed then was indeed FMD, however, they consider it more likely that lameness in sheep on 20 February was FMD and on 10 February not, although this is speculative. Clinical disease in cattle was dated back to 16 February based on the lesions, so the timing for "first disease observed" depends on whether it was in sheep on 10th otherwise it was first in cattle on 16 February, which the FMD experts from IAH consider is most likely. In addition the timing of when the animals got infected has to take incubation period into account to find the infection period. Taking the incubation period into account the sheep may have been exposed between 25 January-4 February if disease was indeed present on 10 February, but the period of exposure was likely 4 February- 
14 February if disease in sheep was on 20 February However, if cattle were the species in which infection was introduced (as thought most likely by the FMD experts), the most probable exposure period was from 2-12 February.

\subsection{Meteorological data}

Detailed meteorological information was available for the whole period including observations from the Met Office's observation data bank, and numerical weather prediction (NWP) data from the Met Office's Unified Model and the Danish Meteorological Institute's DMI-HIRLAM model.

For the Heddon-Ponteland analyses we have in retrospect included additional data from the hourly weather reports from Newcastle Airport and Newcastle Weather Centre; the first being located within $2 \mathrm{~km}$ of the Ponteland outbreak and the second in the Newcastle city centre approximately 7$8 \mathrm{~km}$ to the east.

The NAME, DERMA and LSMC models can run on outputs from numerical weather prediction models. The NAME model used input from the Met Office's Unified Model, and DERMA and LSMC from the Danish Meteorological Institute's numerical weather prediction model (DMI-HIRLAM). The numerical weather prediction data, which were available to LSMC on a $16 \mathrm{~km} \times 16 \mathrm{~km}$ grid, included the following fields: wind speed, direction, near surface temperature, relative humidity $(\mathrm{RH})$, cloud cover, precipitation, surface heat flux, boundary layer depth and Monin-Obukhov length.

The synoptic weather charts revealed that a variety of meteorological conditions were experienced in the Newcastle area between 25 January and 24 February. Apart from a brief spell on 29 January and again on 9 February, the first part of the period was dominated by low-pressure conditions. The weather then changed significantly to higher pressure between 12 and 22 February. On the 23 and 24 February low pressure once again dominated.

For much of the period, i.e. 8, 9, and 12-22 February, it was dry with no rainfall recorded at Newcastle Weather Centre. Newcastle Airport recorded only a total of $8 \mathrm{~h}$ when the $\mathrm{RH}$ was below $60 \%$ (airborne FMD virus is inactivated at RH less than 55 to $60 \%$ ). Of these, three were during the afternoon of 12 February and the remainder from 14 to 18 on 14 February. Temperatures ranged from $-5^{\circ} \mathrm{C}$ on 1 February to $+12^{\circ} \mathrm{C}$ on 14 February. The coldest periods were experienced during the light wind, anticyclonic nighttime conditions. Overall, virus viability would have been high during the full period.

A meteorological local weather database was created consisting of hourly observations extracted by hand from the Newcastle Airport observations. The database includes observed wind speed and wind direction data for the period 25 January through 24 February (Gloster et al., 2002).

Whilst nearly all wind directions were experienced, there were a total of $495 \mathrm{~h}$ when local winds were in the Southwesterly sector $170-340^{\circ}$.
From the database of meteorological observations we have counted the hours during the possible infection period (estimated as 25 January to 24 February) when airborne virus could have been transported from Burnside Farm to Prestwick Hall Farm at Ponteland during low wind speed stable conditions. During this period we recorded a total of $337 \mathrm{~h}$ when wind speeds were lower than $5 \mathrm{kts}(2.6 \mathrm{~m} / \mathrm{s})$ at the same time as the wind directions were in the Southwesterly sector (between $170-340^{\circ}$ ). In addition, there were $143 \mathrm{~h}$ of recorded calm (reported as $0 \mathrm{kts}$ ) conditions (less than $\sim 0.5 \mathrm{~m} / \mathrm{s}$ ). Of these, $113 \mathrm{~h}$ can be allocated to the Southwesterly sector by use of the direction distribution recorded for the $1 \mathrm{kts}$ wind speeds.

\section{Modelling of the virus plume from Burnside Farm}

Accurate modelling of atmospheric dispersion can be quite a challenge, particularly during stable stratified low-wind conditions as prevailed over hilly Northumberland during February 2001. In these situations it is believed that we benefit from investigating the dispersion by looking at the ensemble of several atmospheric flow and dispersion models.

In the spring of 2001, during the period of the outbreaks, we produced daily airborne disease spread calculations whenever a large pig farm was identified as infected. Pig farms are most critical because pigs produce by far the most concentrated virus plumes, cf. Sørensen et al. (2001). We ran four different models in real time: two developed in the UK (10 km Gaussian plume and NAME) and two in Denmark (DERMA and LSMC/RIMPUFF), and handed over the model results to the UK veterinary authorities.

Here follows a short description of the various long-range and short-range models used. A more detailed description of the models and their application to the FMD UK 2001 outbreaks is given by Gloster et al. (2002).

\section{$10 \mathrm{~km}$ Gaussian plume model}

The "10 km Gaussian plume model", developed in 1980 for the specific purpose of predicting the local area at risk from an FMD virus source (Gloster, 1981; Gloster et al., 1982) was used both in the predictive and subsequent epidemiological analysis. Meteorological data, taken from the nearest meteorological observing station was input to the model together with virus emission information. The model calculates the daily and total inhaled virus dosage at $1 \mathrm{~km}$ intervals from the source. This model takes no account of topography.

\section{NAME}

The NAME model, originally developed to provide emergency response to nuclear accidents, volcanic eruptions, major chemical releases and routine daily predictions of air quality was adapted to calculate downwind concentrations at $1 \mathrm{~km}$ intervals (Ryall and Maryon, 1998). The model uses 

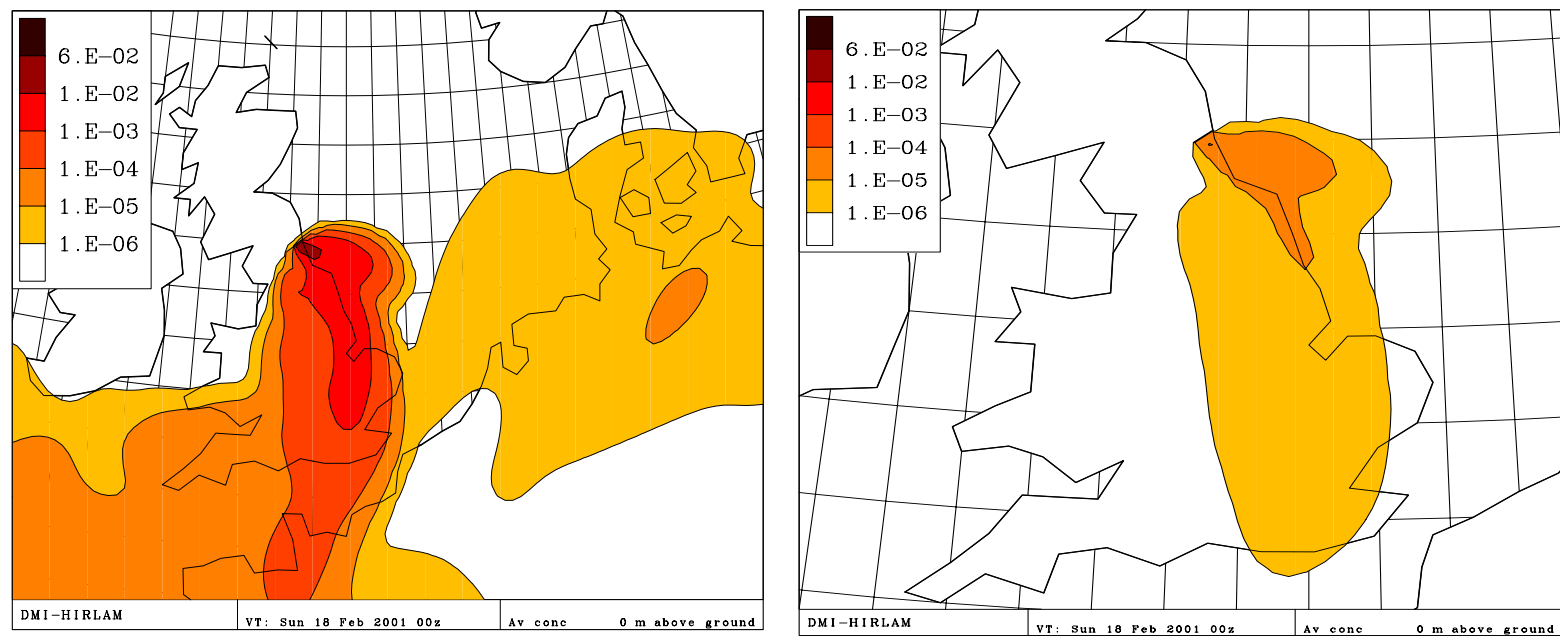

Fig. 1. Outbreak at Burnside Farm - Long-range prediction. Virus plume from Burnside Farm, Heddon-on-the-Wall, simulated by the DERMA long-range model. The contours indicate 24-h average FMD virus concentrations in units of TCID $50 / \mathrm{m}^{3}$ for 17 February 2001. The left figure shows a calculation based on virus excretion data for pigs infected with historical stains of virus that were later found to be excreted in much greater amounts than the UK 2001 strain. Therefore these results represent a "worst-case" scenario. The right figure shows the results obtained later in the epidemic when virus excretion data were changed to those obtained from pigs infected with the UK 2001 strain, all other data remaining unchanged.

three dimensional wind fields and other meteorological data from the Met Office's numerical weather prediction model (the Unified Model).

\section{RIMPUFF}

The real-time emergency preparedness and decision support model RIMPUFF (Mikkelsen et al., 1984; Mikkelsen et al., 1997), embedded in the Local Scale Model Chain (LSMC) which includes an integral meteorological pre-processor (Astrup et al., 2001) and the LINCOM wind models, was also applied in both predictive mode and for retrospective analyses.

In predictive mode, winds over local scale topography and roughness variations were modelled by the wind model LINCOM-Z0 (this model accounts for roughness changes and neutral flow over topography). During the outbreak, real-time calculations were performed with this model on a $500 \times 500 \mathrm{~m}$ grid covering a $40 \times 40 \mathrm{~km}$ domain.

Subsequently, the LINCOM-T model was applied to calculate streamlines in stable stratified low-wind conditions. LINCOM-T is specially designed for calculating stratified wind fields over topography. These calculations were performed with a $250 \times 250 \mathrm{~m}$ grid resolution.

The RIMPUFF model releases virus particles in puffs, a single puff containing the equivalent of $10 \mathrm{~min}$ release. The puffs grow in size due to local turbulence; they rise due to the growth and follow the local winds.

\section{DERMA}

The Danish Emergency Response Model of the Atmosphere (DERMA) is developed at the Danish Meteorological Institute (DMI), where it is used mainly for nuclear emergency preparedness purposes (Sørensen, 1998). DERMA, which is an atmospheric long-range dispersion model describing plumes at downwind distances greater than about $20 \mathrm{~km}$, makes use of high-resolution data available from the various numerical weather prediction models at DMI. DERMA was used in the early stages of the UK 2001 FMD epidemic for assessments of the risk of infection for the European Continent due to long-range transport of virus from infected premises in the UK (Alexandersen et al., 2002b, 2003). At this stage of the epidemic the UK virus had been identified as a member of the Pan Asia group of strains but its aerobiological characteristics, in particular the amount excreted by infected animals, was unknown. Once these parameters had been determined experimentally (Alexandersen and Donaldson, 2002), it became clear that long-range atmospheric disease spread was highly unlikely.

\subsection{Dispersion analysis}

The dispersion models were run for the period 3-24 February. As the Burnside Farm contained hundreds of pigs it raised concerns about the risk of airborne spread not only in the local area but also more distantly, including possible transmission to the Continent.

The risks of airborne spread were first analysed using data for historical strains of virus, which are excreted in high 


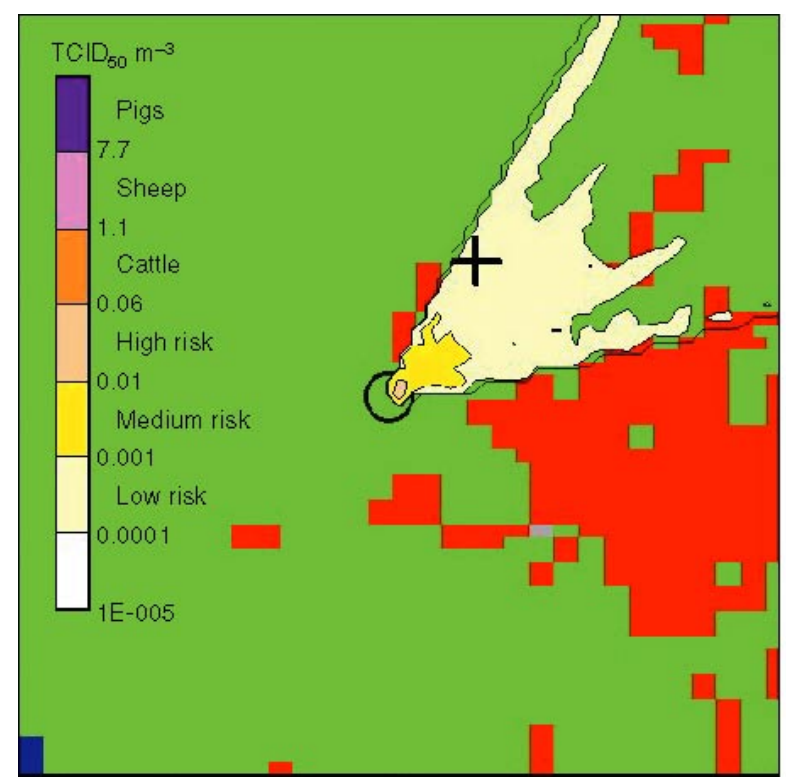

a

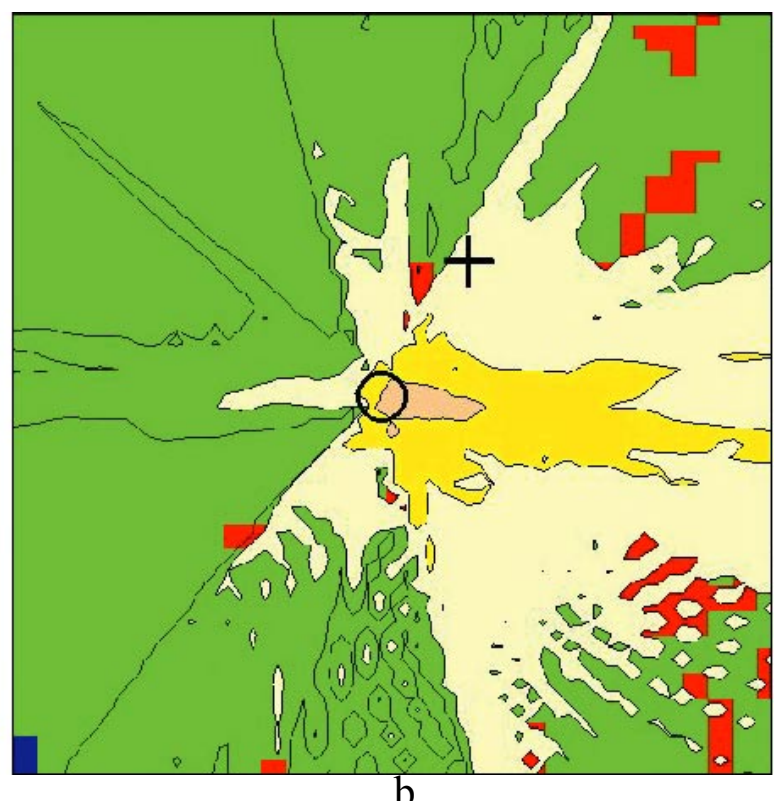

b

Fig. 2. Outbreak at Burnside Farm - Local scale dispersion. RIMPUFF predicted virus dose footprints in units of $\left(\mathrm{TCID}_{50} / \mathrm{m}^{3}\right)$ from Burnside Farm, Heddon-on-the-Wall (FMD outbreak 4). The different infection levels for cattle, sheep and pigs are shown on the legend. The input data for virus excretion are those determined experimentally for the type O UK 2001 strain of virus. The left figure shows the predicted 24-h average concentration contour lines in units of $\left(\mathrm{TCID}_{50} / \mathrm{m}^{3}\right)$ from Burnside Farm over Northumberland for 14 February. The right figure shows the infective dose footprint in units of $\left(\mathrm{TCID}_{50} / \mathrm{m}^{3}\right)$ obtained by selecting the daily maximums from all 22 daily averaged footprints in the period 3 to 24 February 2001. Legend: $O=$ Burnside Farm, Heddon, $+=$ Prestwick Hall Farm, Ponteland, Domain $30 \mathrm{~km} \times 30 \mathrm{~km}$.

quantities by infected pigs (Donaldson et al., 1982; Sørensen et al., 2000). These therefore gave "worst-case" scenarios for predicted spread. Once data for the UK 2001 strain of virus became available these were used instead.

Both the local-scale RIMPUFF and the long range DERMA model have previously been used for the retrospective estimation of the dispersion of the FMD virus (Sørensen et al., 2000, Sørensen et al., 2001). Calculations performed showed that the long-range DERMA calculations gave similar results to the long range NAME model.

The dispersion models treat FMD virus as a depositing aerosol. Model outputs were post-processed to produce 24$\mathrm{h}$ average concentrations in units of $\mathrm{TCID}^{1}{ }_{50} / \mathrm{m}^{3}$ at ground level - i.e. the results were daily mean infective dose footprints in the surroundings of infected premises.

Firstly the amounts of virus emitted from the outbreak at Burnside Farm were calculated using the original Virus Production Model (VPM) (Sørensen et al., 2000). But as new experimental virus excretion data became available for the UK 2001 strain of virus (Alexandersen and Donaldson, 2002), the predictions were all re-calculated. This immediately resulted in a decrease of concentrations of several orders of magnitude (cf. Fig. 1).

\footnotetext{
${ }^{1}$ Tissue Culture Infective Dose
}

Figure 1a shows a prediction of long-range virus dispersion from Burnside Farm calculated by DERMA using "worst-case" virus excretion estimates. The calculations show large temporal and spatial variations in the plume position and spread. In comparison Fig. 1b shows similar results using the experimentally determined excretion rates for the UK 2001 strain of virus. Also the NAME model was run for several pig outbreaks using input data from the Virus Production Model, with the UK2001 strain and meteorological data generated by the Met Office's operational Mesoscale weather prediction model. DERMA and NAME gave quantitatively similar results. Once the virus production model was updated with data for the actual UK2001 virus strain, the risk of long distance spread of the disease to Europe through airborne transport was concluded to be extremely low.

On the local scale, airborne transmission was modelled in real time using the $10 \mathrm{~km}$ Gaussian plume dispersion model and the Local Scale Model Chain pre-processor and RIMPUFF with additional input on local scale topography. Both models required real-time meteorological data, which were obtained from the Met Office, UK and from the Danish Meteorological Institute, respectively. For the subsequent epidemiological study, more local and detailed hourly meteorological observational data were available for the whole period. 


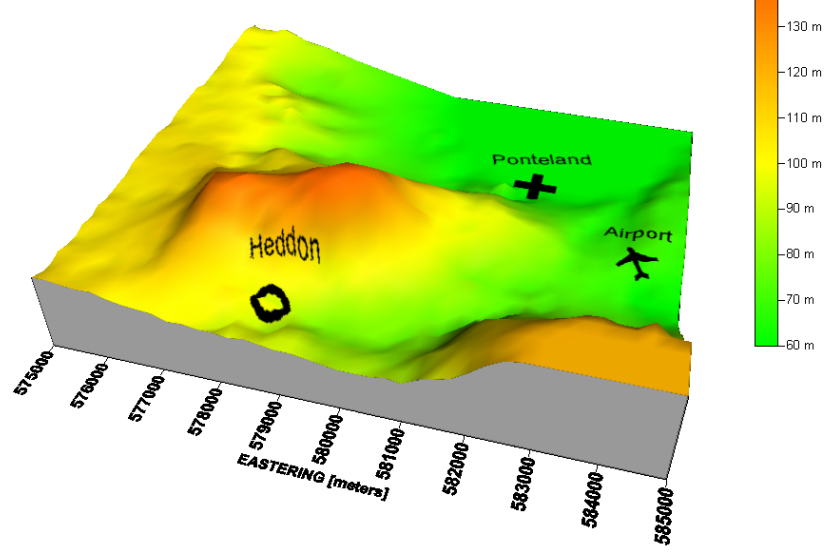

Fig. 3. The Heddon - Ponteland local topography. The circle indicates Burnside Farm, Heddon-on-the-Wall. The cross near Ponteland shows the location of one of the farms where local spread occurred (Prestwick Hall Farm). Also shown is Newcastle Airport from where local meteorological data was obtained. Elevation changes more than $80 \mathrm{~m}$ over the $10 \mathrm{~km}$ by $10 \mathrm{~km}$ area, dominated by the big bluff located immediately to the north of Heddon.

The two local area models (10 km Gaussian plume and RIMPUFF) were also run initially with virus production data from VPM (Sørensen et al., 2000) for Burnside Farm. Both models at first showed huge potential for local scale transmission. However, when the actual UK2001 virus data were inserted these models also predicted less risk of local airborne disease spread.

RIMPUFF can include local scale topography and landuse information via its local scale pre-processor that calculates local wind fields and turbulence estimates. In this case we applied a $500 \times 500 \mathrm{~m}$ local scale grid. DMI-HIRLAM numerical weather data are therefore modified locally by the local-scale LINCOM flow and turbulence model suite. One of these models, the LINCOM-Z0 model, takes the influence of the ground into account, i.e. the topography and the pattern of surface roughness. This model was applied during the early phase real-time assessments.

Another LINCOM Model, the mean wind model LINCOM-T (Dunkerley et al., 2001), is specially designed for calculation of stable and unstable stratified flow fields over topography during low wind speed conditions. This model was applied in the subsequent epidemiological assessments of Burnside Farm.

Figure 2a shows a RIMPUFF prediction of a mean infective FMD dose footprint over a $30 \mathrm{~km}$ by $30 \mathrm{~km}$ area in Northumberland resulting from the estimated virus production from outbreak FMD4 for 14 February 2001. The assumed infection thresholds for cattle, sheep and pigs are shown on the legend.

Figure $2 \mathrm{~b}$ shows the corresponding maximum 24-h average concentration over the area obtained from the 22 daily footprints (like Fig. 2a) during the period 3 February to
24 February 2001. Apparently from the plots, none of the doses exceeded the assumed threshold for infecting cattle $\left(0.06 \mathrm{TCID}_{50} / \mathrm{m}^{3}\right)$. Reported minimum infective doses are based on experiments involving short-term exposure periods, which are extrapolated to 24-h average concentration thresholds in the legends in Fig. 2. It is not known, however, whether a short-time exposure to a large virus concentration equates to the same dose when less virus is inhaled over a longer period (Alexandersen and Donaldson, 2002).

The "10 km model" estimated that during the first period animals within $3 \mathrm{~km}$ of the source in a sector from north to southeast would have been exposed to total doses of up to 5.0 C.I.U. ${ }^{2}$ and from northwest to southeast a total dosage of between 0.1 and 1.0 C.I.U. out to the limit of the model. Detailed analyses of the results of these models, in particular of the dispersion models, are being published elsewhere (Gloster et al., 2002).

\section{Airflow over the Heddon-Ponteland topography dur- ing low-wind stable conditions}

Over extended periods in the beginning of February 2001 warm Atlantic air was advected up over the UK from the south. Over Northumberland, which was partly snow covered due to prevailing winter conditions in January 2001, the warm Atlantic air at times became strongly stably stratified and exhibited profound low wind conditions.

Under low-wind stable conditions it is well known that the corresponding stratified airflow can interact with the local topography, in particular with hills and slopes, and flow around rather than over the hills.

The effects of neutrally stratified flow and its interaction with hilly terrain and changes in surface roughness have already been included in the RIMPUFF real-time calculations via the LSMC LINCOM-Z0 model (Astrup et al., 1997). However, for FMD virus plumes, submerged within stratified flow of low wind and being advected over hilly terrain, the wind direction in particular can be significantly modified.

Burnside Farm is located in Heddon-on-the-Wall on the northern banks of the river Tyne immediately to the west of Newcastle, cf. Fig. 3. Immediately to the north of Burnside Farm there is a small ridge, reaching a maximum height of $140 \mathrm{~m}$, running southwest to northeast (see Fig. 3). Under stable atmospheric conditions this feature is likely to influence the wind flow in the area. The location of Burnside Farm at Heddon (O), the secondary outbreak at Prestwick Hall Farm (+), the Newcastle Airport and the topography are also shown.

To study the effect of this topography in detail, we implemented, in a subsequent study, the LINCOM-T wind model, which is specially designed to account for thermally stratified flows' interaction with topography, such as valley breezes and nocturnal drainage winds. LINCOM-T was

\footnotetext{
${ }^{2}$ C.I.U.: Cattle Infectious Units
} 
originally designed to model effects of stratified airflow including drainage flow and valley breezes over hilly terrain (Dunkerley et al., 2002).

\subsection{The LINCOM-T model}

The LINCOM flow models are all based on simplified linearized versions of the Navier-Stokes equations and makes use of Fourier transform techniques to generate equations which can be solved partly using analytical techniques. Like the other models, LINCOM-T also solves a set of linearized equations for conservation of momentum and mass, but in addition, LINCOM-T encompasses a pre-described vertical thermal stratification. Closure is also here introduced via a first-order spectral diffusivity scheme.

In LINCOM-T, thermal effects are accounted for by specifying the vertical form of the potential temperature field $(\bar{\theta})$. Hence $\bar{\theta}$ is a fixed temperature field (not a variable). It is further assumed that can be written in terms of a perturbation to a background value $(\Theta)$, where the perturbation is expressed in variable separable form in a terrain following coordinate system $\left(x, y, z^{\prime}\right)$ such that:

$\theta\left(x, y, z^{\prime}\right)=\tau e^{-z^{\prime} / \lambda}$.

The constants $\tau$ and $\lambda$ are the surface layer's temperature deviation from neutral and its vertical depth, respectively.

These parameters can either be set explicitly (if measurements are available), or be estimated within LINCOM-T from surface layer parameter scaling (such as surface heat flux and surface friction velocity) as available from within the LSMC pre-processor for example.

Equation (1) can then be expressed in Cartesian coordinates $\left(x_{1}, x_{2}, x_{3}\right)$ by substituting $z^{\prime}$ by $x_{3}-h\left(x_{1}, x_{2}\right)$, where $h$ is the terrain height. The horizontally Fourier transformed governing

$$
\begin{aligned}
& \left(i k_{1} U+i k_{2} V\right) \tilde{u}+i k_{1} \tilde{p}+K \frac{\partial^{2} \tilde{u}}{\partial x_{3}^{2}}=0 \\
& \left(i k_{1} U+i k_{2} V\right) \tilde{v}+i k_{2} \tilde{p}+K \frac{\partial^{2} \tilde{v}}{\partial x_{3}^{2}}=0 \\
& -\left(i k_{1} U+i k_{2} V\right) \tilde{w}+\frac{\partial \tilde{p}}{\partial x_{3}}+\frac{\partial \tilde{P}}{\partial x_{3}}-K \frac{\partial^{2} \tilde{w}}{\partial x_{3}^{2}}=\frac{g}{\Theta} \tilde{\theta}\left(x_{3}-\tilde{h}\left(k_{1}, k_{2}\right)\right) \\
& -i\left(k_{1} \tilde{u}+i k_{2} \tilde{v}\right)+\frac{\partial \tilde{w}}{\partial x_{3}}=0,
\end{aligned}
$$

where $\tilde{u}, \tilde{v}$ and $\tilde{w}$ are the spectral thermal induced velocity perturbations; $k_{1}$ and $k_{2}$ the horizontal wave numbers; $K$ a spectral diffusivity, and $\tilde{p}$ the thermally induced pressure perturbation. The set of Eq. (2) form a 2nd order linear differential equation in $x_{3}$, which can be solved analytically for $\tilde{u}, \tilde{v}, \tilde{w}$ and $\tilde{p}$. Inverse Fourier transformation of these analytical solutions with terrain boundary conditions then yields the thermal wind components $u, v$ and $w$. The model is extremely fast. A run takes $5-10 \mathrm{~s}$ on a standard PC. See Dunkerley et al. (2001) for details.

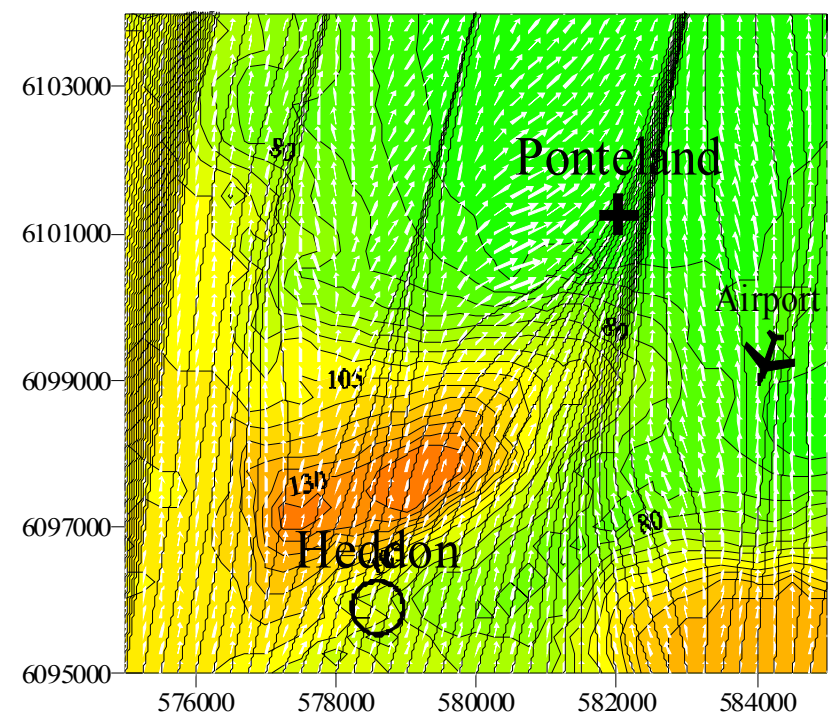

Fig. 4. Lincom-T model output (a stable stratified case). LINCOM$\mathrm{T}$ predicted wind field over Northumberland for the period between 9 February and 10 February, where the atmosphere's stratification was very stable, and winds of low speed prevailed from a southerly direction. Model inputs: wind direction $192^{\circ}$, mean wind speed $1 \mathrm{~m} / \mathrm{s}$; Monin-Obukhov stability length scale $L=+10 \mathrm{~m}$. The figure shows the calculated wind vectors (white arrows) and the corresponding streamlines (black lines) $10 \mathrm{~m}$ above terrain.

\subsection{LINCOM-T model results}

When the UK FMD 2001 outbreak was brought under control, we investigated in greater detail the possibility of airborne transmission for specific outbreaks.

For Burnside Farm, we analysed the flow pattern in the area between Heddon and Ponteland by taking account of its special topography with help from the LINCOM-T model. We performed a study on trajectories emerging from Burnside Farm and investigated under which wind directions and wind speeds these trajectories would go over Ponteland, located $\sim 6 \mathrm{~km}$ to the north east during the prevailing low wind and stable atmospheric conditions.

Figure 3 shows the topography. It is seen that Prestwick Hall Farm (Ponteland) is located downwind from Heddon in southerly winds but behind the ridge, which extends a distance of several kilometers. It could be anticipated that trajectories interact with this ridge, in particular during lowwind stable conditions.

Figure 4 shows LINCOM-T's prediction of wind vectors and trajectories during a low-wind stable case, where the model has been run with a southerly mean input wind direction (input wind direction was $192^{\circ}$ in this case). The wind vectors are seen to be perturbed predominantly on the down slopes and the streamlines are deflected from the hilltops as a consequence of the stable stratification. The streamlines seek a path through the passes and valleys rather than over the hilltops due to the air's stable stratification. The wind 
Table 1. Lincom-T input parameters used for Burnside Farm, Heddon-on-the-Wall, Ponteland: For each of the wind directions $(180,190,200, \ldots 290,300)$, five calculations were performed with the mean wind speed and Monin-Obukhov length scales shown as input parameters. Lincom-T's pre-processor calculated the temperature difference over the stable surface layer $\tau$, and its corresponding depth $\lambda$, cf. Eq. (1). Also the model's corresponding Froude No. (defined as $U^{2} / g \lambda$ ) was calculated. It is a measure for the stable stratified flow's kinetic energy relative to its potential energy.

\begin{tabular}{ccccc}
\hline $\begin{array}{c}\text { Mean wind } \\
U(\mathrm{~m} / \mathrm{s})\end{array}$ & $\begin{array}{c}\text { Stability } \\
L(\mathrm{~m})\end{array}$ & $\tau\left({ }^{\circ} \mathrm{C}\right)$ & $\lambda(\mathrm{m})$ & $\begin{array}{c}\text { Froude } \\
\text { No. }\end{array}$ \\
\hline 1 & 10 & -0.27 & 23 & 1.00 \\
2 & 20 & -0.95 & 52 & 2.25 \\
3 & 33 & -1.60 & 87 & 3.80 \\
4 & 50 & -2.06 & 127 & 5.75 \\
5 & 100 & -1.50 & 208 & 10.50 \\
\hline
\end{tabular}

vectors are seen to reduce their speed on up-slopes, while on the contrary they increase - even quite significantly, as cold air is falling down on the lee of the ridge. The wind speeds do not pick up immediately as the flow goes over the top. Rather the down slope increase in wind speeds appears as a delayed effect on the back slopes. This is due to the inertia (momentum conservation) in the model - it takes time to accelerate the flow. In Fig. 4, streamlines and trajectories are identical because the meteorological conditions were constant over time (hourly mean values).

In direct line-of sight, Ponteland is located on a $220^{\circ}$ bearing $\sim 6.3 \mathrm{~km}$ down wind to the north east of Burnside Farm, Heddon. In Fig. 4, LINCOM-T trajectories emerging from Burnside hits Ponteland with an input mean direction of $192^{\circ}$. The deflection caused by the stratified flows interaction with the topography is therefore $\sim 28^{\circ}$ in this case.

During the period in question atmospheric stability was either stable, neutral or slightly unstable. There were no periods of strong instability. Nevertheless, to demonstrate the ability of LINCOM-T to deal also with unstable stratification we have in Fig. 5 changed the air flows stratification parameter $\mathrm{L}$ from stable to unstable (by just changing the sign on the Monin-Obukhov stability parameter L). Otherwise the input direction and wind speeds have been kept the same as in Fig. 4. In this case, the wind vectors tend to turn upslope, and the trajectories seeks to climb the hills (like in a valley breeze) rather than drain down the valleys. The trajectory that starts at Burnside Farm, Heddon is seen to veer far off to the west of Ponteland in this case. Overall, the airflow over the Heddon-Ponteland topography appears, as modeled by LINCOM-T, to be strongly influenced by the local topography in combination with stratification effects.

We further investigated a range of conditions (direction, speed and stability) under which trajectories of virus released from Heddon reached Ponteland.

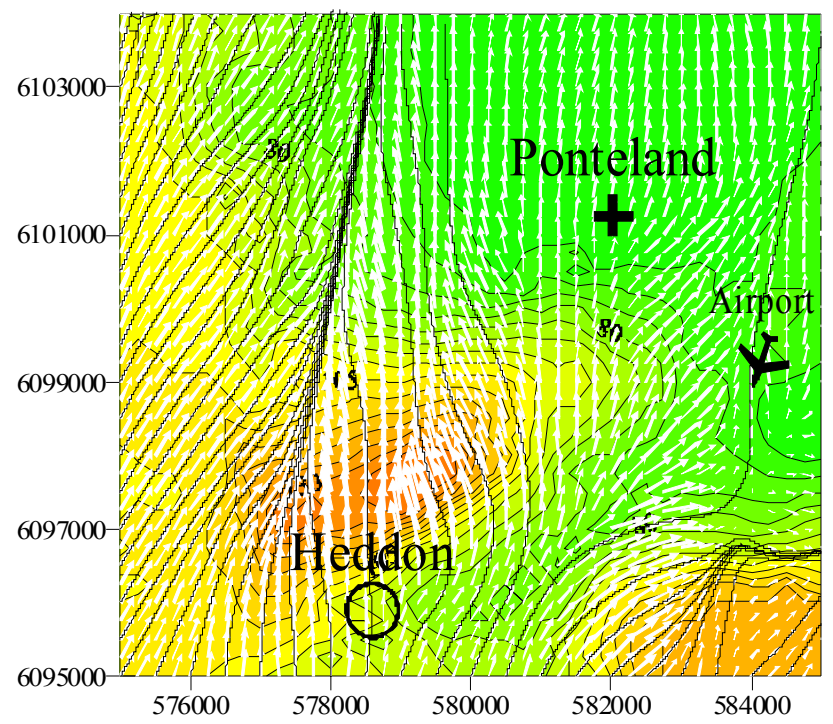

Fig. 5. Lincom-T model output (an unstable stratified case). This figure shows the model response to the same wind speed and direction inputs as performed in Fig. 4, but for a case where the temperature stratification (vertical temperature gradient) were deliberately changed from stable ( $L=+10$, cf. Fig. 4$)$ to unstable ( $L=-10 \mathrm{~m}$ in this figure).

We varied the input synoptic wind direction in steps of $10^{\circ}$ from $180^{\circ}$ to $300^{\circ}$, and calculated for each of these directions trajectory plots corresponding to Fig. 4, for five bins of wind speed and stability as shown in Table 1 .

The values of the Froude number shown in Table 1 for a number of mean wind speeds indicate that the flow is subcritical at the lowest wind speeds. This implies that the flow will tend to go around rather than over the hill in this case.

Figure 6 shows the resulting plots for a fixed input mean wind direction of $190^{\circ}$. It is seen that the local stratification effects are strongest with the lowest $(\mathrm{U}=1, \mathrm{~m} / \mathrm{s})$ input wind speed, and that the effect of stratification almost vanishes at $\mathrm{U}=5 \mathrm{~m} / \mathrm{s}$

With the lowest wind speed applied $(1 \mathrm{~m} / \mathrm{s})$ the results showed that Ponteland was hit by the stable stratified, topography-deflected Burnside farm trajectories whenever the model's mean input direction was in the range 180 to $210^{\circ}$; that is, whenever the input wind direction for the model was within an $\sim 30^{\circ}$ wide sector.

As the wind speed increased, this sector became smaller, and at $5 \mathrm{~m} / \mathrm{s}$, this sector had shrunk to only a few degrees centred about the line of sight $220^{\circ}$ bearing.

\section{Conclusions}

We have modelled the infection dose footprints and investigated the trajectories of possible airborne transmission from a critical outbreak in a pig farm (Burnside Farm) at Heddon- 

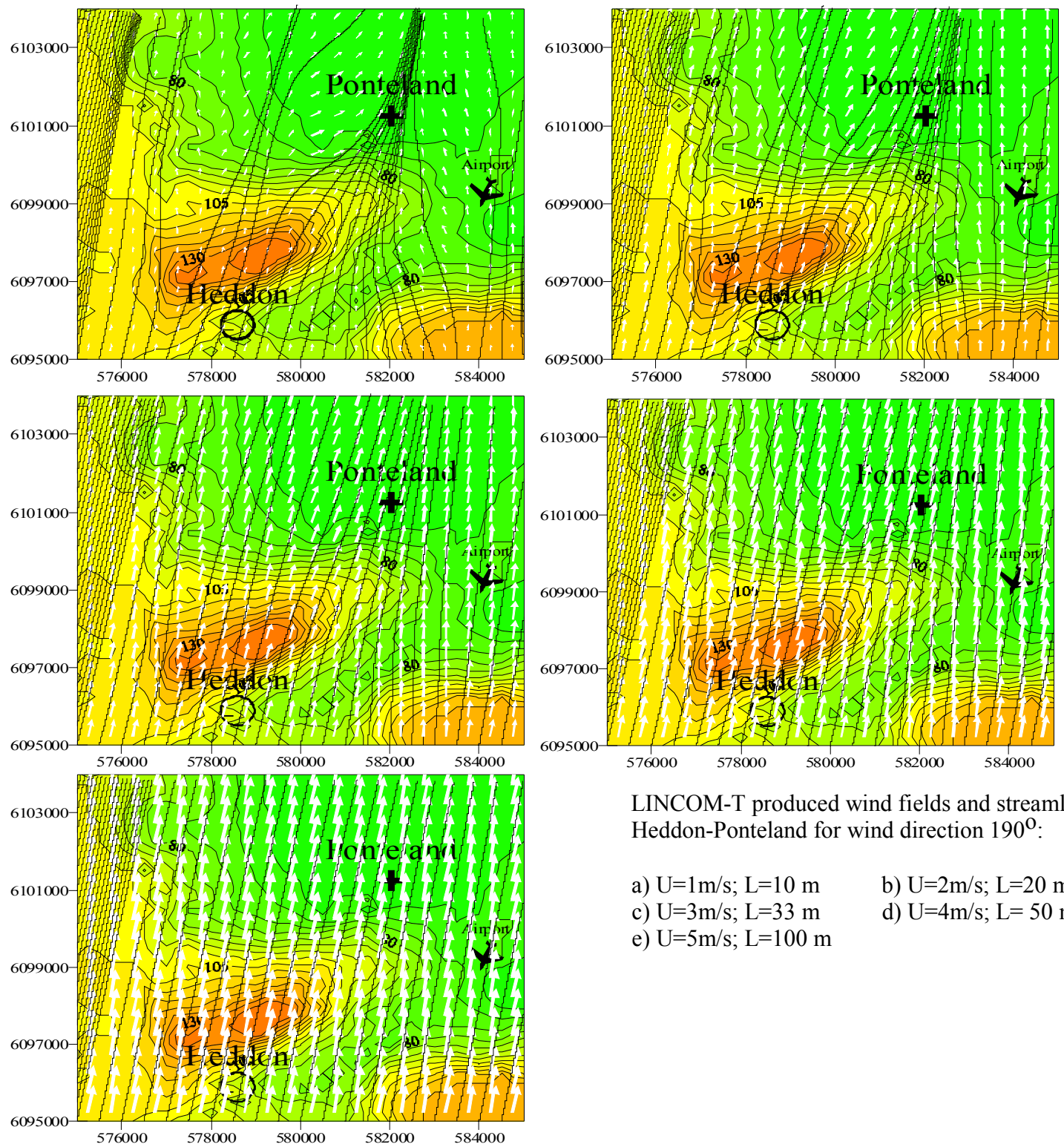

LINCOM-T produced wind fields and streamlines over Heddon-Ponteland for wind direction $190^{\circ}$ :
a) $\mathrm{U}=1 \mathrm{~m} / \mathrm{s} ; \mathrm{L}=10 \mathrm{~m}$
b) $\mathrm{U}=2 \mathrm{~m} / \mathrm{s} ; \mathrm{L}=20 \mathrm{~m}$
c) $\mathrm{U}=3 \mathrm{~m} / \mathrm{s} ; \mathrm{L}=33 \mathrm{~m}$
d) $\mathrm{U}=4 \mathrm{~m} / \mathrm{s} ; \mathrm{L}=50 \mathrm{~m}$
e) $\mathrm{U}=5 \mathrm{~m} / \mathrm{s} ; \mathrm{L}=100 \mathrm{~m}$

Fig. 6. Lincom-T model output for varying mean wind speeds and stability. LINCOM-T produced wind fields and streamlines over the Heddon-Ponteland site for a fixed mean wind direction of $190^{\circ}$. The figures show the LINCOM-T model response to increasing mean wind speed $U$, starting with: upper left $1 \mathrm{~m} / \mathrm{s}$, upper right $2 \mathrm{~m} / \mathrm{s}$; middle left $3 \mathrm{~m} / \mathrm{s}$; middle right $4 \mathrm{~m} / \mathrm{s}$ and lower left $5 \mathrm{~m} / \mathrm{s}$. The corresponding stability parameter $L$ has been set in the five cases to reflect the effects on stability from increasing wind speeds.

on-the-Wall, Northumberland at the start of the foot- and mouth disease epidemic in the UK in February 2001.

Simulation of the virus plumes from the farm were performed with four different dispersion models all run with actual weather data during the period of airborne virus emission, estimated to have commenced around $\sim 1$ February, and to have ended on 24 February 2001 when the animals were culled.

The daily virus excretion rates from Burnside Farm were calculated in the first series of analyses from estimations of the number of infected pigs in the premises, the stage of their clinical disease and historical data from a virus production model. Later, when daily excretion data became available from experimental investigations with the UK 2001 strain, the simulations were re-run using those input data.

The results obtained showed that:

1. The risk of airborne virus transmission from the outbreak at Burnside Farm over intercontinental ranges was extremely low due to the limited excretion of airborne virus by pigs infected with the O UK 2001 virus strain. 
2. The risk of local scale inter-farm airborne spread depended strongly on downwind distance. For the Burnside Farm Heddon-Ponteland investigation, the daily infection doses as predicted by LSMC/RIMPUFF were designated "high" (cf. Fig. 2) and appeared just below the experimentally determined minimum infection dose required to infect cattle.

3. LINCOM-T model calculations showed that the local topographical features, combined with stable wind stratification and low wind speed, would have caused virus plumes from Heddon to pass over farms at Ponteland whenever the synoptic winds were from south-south westerly directions in the wide range between $\sim 180$ and $210^{\circ}$

4. Infection at Prestwick Hall is consistent with airborne disease spread from Burnside Farm. During the first half of February 2001 there were South-westerly winds often combined with stable stratified atmospheric conditions over Northumberland. These conditions would have produced narrow plumes containing high concentrations of virus.

\section{References}

Alexandersen, S. and Donaldson, A. I.: Further studies to quantify the dose of natural aerosols of foot-and-mouth disease virus for pigs, Epidemiology \& Infection, 128, 313-323, 2002.

Alexandersen, S., Brotherhood, I., and Donaldson, A. I.: Natural aerosol transmission of foot-and-mouth disease virus to pigs: minimal infectious dose for strain O1 Lausanne, Epidemiology \& Infection, 128, 301-312, 2002a.

Alexandersen, S., Kitching, R. P., Mansley, L. M., and Donaldson, A.I.: Clinical and laboratory investigations of five outbreaks during the early stages of the 2001 foot-and-mouth disease epidemic in the United Kingdom, Report of the Session of the Standing Technical Committee of the European Commission for the Control of Foot-and-Mouth Disease held at Izmir, Turkey, 17-20 September, 2002, Rome: FAO 2002 Appendix 5, 59-66, 2002 b.

Alexandersen, S., Kitching, R. P., Mansley, L. M., and Donaldson, A.I.: Clinical and lLaboratory investigations of five outbreaks during the early stages of the 2001 Ffoot-and-Mouth disease epidemic in the United Kingdom, Vet. Record, 19 April 2003.

Astrup, P., Mikkelsen, T., and Deme, S.: METRODOS: Meteorological pre-processor chain, Phys. Chem. Earth B, 26, 105-110, 2001.

Astrup, P.; Jensen, N.O., and Mikkelsen, T.: A fast model for mean and turbulent wind characteristics over terrain with mixed surface roughness, Radiat. Prot. Dosim.,73, 257-260, 1997.
Donaldson, A. I., Ferris, N. P., and Gloster, J.: Air sampling of pigs infected with foot-and-mouth disease virus: comparison of Litton and cyclone samplers, Res. Vet. Sci., 33:384-5, 1982.

Donaldson, A.I. and Alexandersen, S.: Predicting the spread of foot and mouth disease by airborne virus, Rev. sci. tech. Off. int. epiz., 21, 3, 2002.

Donaldson, A. I.; Alexandersen, S.; Sørensen, J. H., and Mikkelsen, T.: Relative risks of the uncontrollable (airborne) spread of FMD by different species, The Vet. Record, 148, 19, 602-604, 2001.

Dunkerley, F.; Moreno, J.; Mikkelsen, T., and Griffith, I. H.: LINCOM wind flow model: Application to complex terrain with thermal stratification, Phys. Chem. Earth B , 26, 839-842, 2001.

Mikkelsen, T., Larsen, S. E., and Thykier-Nielsen, S.: Description of the Ris $\varnothing$ puff diffusion model, Nuclear Technology, 67, 56-65, 1984.

Mikkelsen, T., Thykier-Nielsen, S., Astrup, P., Santabarbara, J. M., Sørensen, J. H., Rasmussen, A., Robertson, L., Ullerstig, A., Deme, S., Martens, R., Bartzis, J. G., and Pasler-Sauer, J. : METRODOS: A comprehensive atmospheric dispersion module, Radiat. Prot. Dosim., 73, 45-56, 1997.

Mikkelsen, T., Thykier-Nielsen, S., Astrup, P., Santabárbara, J. M., Havskov Sørensen, J., Rasmussen, A., Deme, S., and Martens, R.: An operational real-time model chain for now-and forecasting of radioactive atmospheric releases on the local scale. In: Air pollution modeling and its application 12. 22. NATO/CCMS international technical meeting, Clermont-Ferrand (FR), 2-6 June 1997a, edited by Gryning, S.-E. and Chaumerliac, N., Plenum Press, New York, NATO Challenges of Modern Society, 22, 501508, 1998.

Gloster, J., Blackall, J., Sellers, R. F., and Donaldson, A. I.: Forecasting the spread of foot-and-mouth disease, Vet. Rec., 108, 370-374, 1981.

Gloster, J., Champion, H. J., Sørensen, J. H., Mikkelsen, T., Ryall, D. B., Astrup, P., Alexandersen, S., Donaldson, A. I.: Airborne transmission of foot-and-mouth disease virus from Burnside Farm, Heddon-on-the-Wall, Northumberland, during the 2001 epidemic in the United Kingdom, Vet. Record, 152 , 525533, 2003.

Gloster, J., Sellers, R. F., and Donaldson, A. I.: Long distance transport of foot-and-mouth disease virus over the sea, Vet. Rec., 110, 47-52, 1982.

Sørensen, J. H.: Sensitivity of the DERMA long-range dispersion model to meteorological input and diffusion parameters, Atmos. Environ., 32, 4195-4206, 1998.

Sørensen, J. H., Jensen, C. Ø., Mikkelsen, T., Mackay, D. K., and Donaldson, A. I.: Modelling the atmospheric dispersion of foot-and-mouth disease virus for emergency preparedness, Phys. Chem. Earth, 26, 93-97, 2001.

Sørensen, J. H., Mackay, D. K., Jensen, C. O., and Donaldson, A. I.: An integrated model to predict the atmospheric spread of foot-and-mouth disease virus, Epidemiol. Infect., 124, 577- 590, 2000 . 